\title{
DETERMINANTS OF CHILD IMMUNIZATION UNDER EXPANDED PROGRAMME ON IMMUNIZATION (EPI) IN A RURAL SETTING OF BANGLADESH
}

\author{
ADHIKARY $\mathrm{M}^{1}$, HAQUE $\mathrm{R}^{2}$, TANIRA $\mathrm{S}^{3}$
}

\begin{abstract}
Objective: The aim of the study was to evaluate immunization status of children aged 12 to 23 months and to find out reasons for non-immunization and partial immunization, if any, under national Extended Programme on Immunization (EPI).

Methods: This cross sectional study was done among a representative sample of 249 mothers/ principal caretakers of children under 2 years of age from households with varying socioeconomic status and with varying levels of education, from a rural setting, village Mulaid under Telihati union at Sreepur Upozilla under Gazipur district, in between March and June of 2011.

Results: The study found that 221 (88.76\%) of the children were fully immunized (FI) with $B C G, P E N T A 3$, OPV3 and measles; 27 children (10.84 \%) were partially immunized and only 1 (0.40\%) was non-immunized according to the recommendations used. Four of the children were missing full coverage of PENTA, seven of the children were missing OPV, 8 children were missing BCG where as 9 children were missing measles. The vaccination rate increased with an increase in the age of the children and the education level of the mother. Children of older mothers were more likely to have had the correct vaccinations. The mothers' knowledge of and attitudes to vaccination showed a strong relationship with the vaccination status of their children. When the coverage rate for each vaccine was taken separately, the economic level of the households significantly affected the vaccine coverage. Most vaccinations occurred in public outlet agencies. Postponement of immunization due to the illness of the child, mother's lack of information about place, schedule and eligible age of immunization, parental lack of knowledge for the need for vaccines and family size constituted the main reasons for partial /onimmunization. A significant number of children in this study were found to be lacking recommended immunizations for age; a large number of their mothers stated that they did not know further vaccines were needed. Future efforts targeting immunization must emphasize better education of parents.

Conclusion: It was concluded that lack of appropriate information is still the main hurdle for success of primary immunization in rural areas. Improvement could be achieved by improving IEC activities especially among females, as well as making this program success by putting all efforts in the case of EPI.
\end{abstract}

Keywords: EPI, immunization coverage, drop out.

J Dhaka Med Coll. 2013; 22(2) : 201-206.

\section{Introduction:}

Expanded programme on immunization (EPI) target diseases are one of the leading causes of high childhood morbidity and mortality as evidenced by high IMR (Infant mortality rate) in developing countries ${ }^{1}$. Immunization is thereby a timely step for prevention of mortality and morbidity due to communicable diseases in the $0-5$ yrs of age group.
The WHO rates immunization as one of the interventions with a large potential impact on health outcomes ${ }^{1}$. EPI aims at completing the primary immunization (BCG, PENTA3, OPV3, and Measles) for all the children by the time children become one year old ${ }^{2}$. However its impact is not even throughout countries ${ }^{3}$. In the past few decades immunization coverage rates have improved sufficiently in developed

1. Dr. Minati Adhikary, Assistant Professor, Department of Community Medicine, Dhaka Medical College, Dhaka.

2. Dr. Rumana Haque, Lecturer, Department of Community Medicine, Dhaka Medical College, Dhaka.

3. Dr. Shaorin Tanira, Coordinator (Health), Manabik Shahajya Sangstha (MSS), Dhaka.

Correspondence: Dr. Minati Adhikary, Assistant Professor, Department of Community Medicine, Dhaka Medical College, Dhaka 
countries, thereby conferring herd immunity, whereas most of the developing countries are still struggling with faltering rates ${ }^{4}$. Despite all the efforts put by governmental as well as non-governmental institutes for $100 \%$ immunization coverage, there are still pockets of low coverage areas. Rural communities constitute one of the high-risk areas for the vaccine preventable diseases ${ }^{2}$. The delivery systems of the immunizations have many inherent problems to which an addition may be made by the people themselves, with their prejudices, conclusions and apathy ${ }^{5}$. Immunization is not only one of the best indicators to evaluate the health outcomes and services distributed across social and economic groups but also one of the most cost-effective interventions to prevent a series of major illnesses, particularly in environments where children are undernourished and die from preventable diseases. Reasons underlying poor coverage has been studied by researchers worldwide and besides other factors, parental knowledge and beliefs have been documented to influence immunization uptake $e^{6,7}$. The challenge for immunization services providers therefore, is to offer parents balanced and comprehensive information about the risks as well as benefits of immunizations. With this background, the present study was carried out to find out immunization coverage among children 12-23 moths of age and reasons behind non/partial immunization.

\section{Methods:}

This cross sectional descriptive study was done between March and June of 2011 in the village Mulaid under Telihati union at Sreepur Upozilla under Gazipur district. This study was done based on the answers on a semistructured questionnaire on 249 mothers/ principal caretakers of children aged 12-23 months. The study was guided by objectives namely, to examine the demographic and socioeconomic household characteristics that determine immunization status among children 12-23 months old in a rural setting and to establish the household demographic factors that influence immunization status among children 12-23 months old. The dependent variable was immunization status, which had three categories; a child being fully immunized, partially immunized and nonimmunized. The independent variables included; income of the household, mothers' education level, mothers' age among other socio-economic and demographic factors. The data was analyzed at three different levels; univariate, bivariate using the Pearson's chi square statistic and multivariate using the multinomial logistic regression model.

\section{Operational definitions used in the study:}

Fully immunized: The child was considered fully immunized if he/she received one dose each of BCG and measles and three doses of PENTA and polio.

Partially immunized: Those who had missed only one vaccine out of the eight primary vaccines.

Non-immunized: Those children who had received nil vaccine up to their first birthday.

\section{Results:}

The study found out that about 88.76 per cent of the children in age group 12-23 months were fully protected by immunizations. The performance of PENTA and OPV were higher in comparison to measles vaccine. The scar was absent in about 16 percent of BCG immunized children. The total drop out rate of BCG \& measles was calculated to be 3.21 per cent and 3.61 per cent respectively. The main source of immunization was health centre/sub-centre. The major reasons of the failure of immunization were related to various kinds of obstacles including physical proximity and parental lack of attitude (carelessness) for the need for vaccines $(29 \%)$, illness (14\%), need for reminders (36\%), postponement of immunization due to the illness of the child, mother's lack of information about place, schedule and eligible age of immunization and business of mothers in work were identified by parents as reasons for missing vaccines in their children. The main source of knowledge about VPD diseases was reported to be health staff $(88 \%)$. It has been observed that about $88.76 \%$ percent children received all the vaccines (BCG, PENTA, OPV, and Measles) as against about 90 per cent at all Bangladesh 
level. The coverage levels were lower for children of illiterate mothers. Age-appropriate immunization rates were $60 \%$ for 3PENTA \& 3 Polio, $50 \%$ for $1 \mathrm{BCG}$, and $40 \%$ for 1 measles vaccine. First-born children, mother's literacy, and domiciliary visit of health workers were significantly related to age-appropriate immunization. Majority of the Mothers (66\%) themselves took decisions regarding immunization of the child. Sixty six percent of mothers reported side effects after immunizing the children and $80 \%$ reported fever after PENTA.
There were 249 children aged between 12 to 23 months. It was found that 221 (88.76\%) children were fully immunized against all the eight vaccine preventable diseases. The coverage level for individual vaccine is shown in table-I. 27 children $(10.84 \%)$ were partially immunized and only $1(0.40 \%)$ was nonimmunizeed.Mother's lack of knowledge about place, schedule, eligible age of immunization and uncertainty regarding the benefits of immunization was the reported reason for nonimmunization. Parents' literacy status, family type, and mothers occupation were found to have significantly affected the coverage (Table-II).

Table I

Distribution of immunization coverage for individual vaccines.

\begin{tabular}{lcccccccc}
\hline Coverage & \multicolumn{2}{c}{ PENTA } & \multicolumn{2}{c}{ OPV } & \multicolumn{2}{c}{ BCG } & \multicolumn{2}{c}{ Measles } \\
& No. & $(\%)$ & No. & $(\%)$ & No. & $(\%)$ & No. & $(\%)$ \\
\hline Four doses & - & - & - & - & - & - & - & - \\
Three doses & 245 & $(98.39 \%)$ & 242 & $(97.19 \%)$ & - & & - & \\
Two doses & 01 & $(0.40 \%)$ & 03 & $(1.20 \%)$ & - & & - & \\
One dose & 02 & $(0.81 \%)$ & 03 & $(1.20 \%)$ & 241 & $(96.79 \%)$ & 240 & $(96.39 \%)$ \\
Nil & 01 & $(0.40 \%)$ & 01 & $(0.40 \%)$ & 8 & $(3.21 \%)$ & 9 & $(3.61 \%)$ \\
\hline Total & 249 & 249 & 249 & 249 & & & & \\
\hline
\end{tabular}

Table II

Association of different factors with the immunization status of the child.

\begin{tabular}{|c|c|c|c|c|c|}
\hline \multirow{2}{*}{$\begin{array}{l}\text { Variables } \\
\text { Type of Family }\end{array}$} & \multicolumn{2}{|c|}{$\begin{array}{c}\text { Complete } \\
\text { immunization }\end{array}$} & \multicolumn{2}{|c|}{$\begin{array}{l}\text { Partial/non- } \\
\text { immunization }\end{array}$} & \multirow[t]{2}{*}{ Total } \\
\hline & & & & & \\
\hline Nuclear & 140 & $(93.33 \%)$ & 10 & $(6.67 \%) \quad p<0.05$ & 150 \\
\hline Joint & 81 & $(81.81 \%)$ & 18 & $(18.19 \%)$ & 99 \\
\hline \multicolumn{6}{|c|}{ Mother's literacy status } \\
\hline Illiterate & 54 & (72.97\%) & 20 & $(27.03 \%) \quad p<0.05$ & 74 \\
\hline Literate & 167 & $(95.43 \%)$ & 8 & $(4.57 \%)$ & 175 \\
\hline \multicolumn{6}{|c|}{ Father's literacy status } \\
\hline Illiterate & 13 & $(34.21 \%)$ & 25 & $(65.79 \%) \mathrm{p}<0.05$ & 38 \\
\hline Up to High school & 158 & $(98.14 \%)$ & 03 & $(1.86 \%)$ & 161 \\
\hline SSC \& above & 50 & $(100 \%)$ & 0 & (0 \%) & 50 \\
\hline \multicolumn{6}{|l|}{ Mother's occupation } \\
\hline Housewife & 207 & $(98.10 \%)$ & 4 & $(1.90 \%) p<0.05$ & 211 \\
\hline Working & 14 & $(36.84 \%)$ & 24 & $(63.16 \%)$ & 38 \\
\hline \multicolumn{6}{|l|}{ Father's occupation } \\
\hline Labourer & 20 & $(87.30 \%)$ & 43 & $(12.70 \%) \mathrm{p}>0.1$ & 63 \\
\hline Bussiness/service & 166 & $(89.25 \%)$ & 20 & $(10.75 \%)$ & 186 \\
\hline
\end{tabular}


Table-III

Reasons for partial / non immunization of the child.

\begin{tabular}{lcc}
\hline Reason & Children No. & $(\%)$ \\
\hline Child unwell & 4 & $(14.28)$ \\
Negative attitude & 18 & $(64.29)$ \\
Lack of time & 6 & $(21.43)$ \\
\hline Total & 28 & $(100.0)$ \\
\hline
\end{tabular}

Table IV

Results of the logistic regression analysis of the determinants of child immunization

\begin{tabular}{lccc}
\hline Variable & OR & $95.0 \%$ CI & P value \\
\hline Age of mother & & & \\
$15-29$ & $1 "$ & & \\
$30-45$ & 2.20 & $1.25-3.74$ & 0.005 \\
Education & & & \\
No education & $1 "$ & & \\
and primary & & & \\
Secondary and & 2.00 & $1.13-3.51$ & 0.007 \\
university & & & \\
S.E.S & & & \\
Lower & $1 "$ & & \\
Higher & 1.05 & $0.61-1.95$ & 0.80 \\
Walk time & & & \\
$>30$ minutes & $1 "$ & & \\
$<29$ minutes & 3.30 & $1.61-7.02$ & 0.005 \\
Constant & .05 & & 0.000 \\
\hline
\end{tabular}

Table IV shows that accessibil-ity (walking time to facility), age of the mother and mother's level of education were significant predictors of correct vaccination for the child's age. The odds ratio $(\mathrm{OR})$ indicates that walking time to the nearest place of vaccination strongly influenced the correct vaccination sta-tus of the child. Children of mothers who have better access to vaccine services (less than 30 minutes walking time to the nearest place of vaccination) were 3.3 times more likely to have had the cor-rect vaccinations than were children of mothers who have to walk 30 minutes or longer. The mother's age also had a statistically significant influence on the odds of the child being correctly vaccinated. Children of mothers older than 30 years of age were 2.20 times more likely to be correctly vaccinated than were children of mothers younger than 30. The mother's level of education had a statistically significant influence on the odds of the child being correctly vaccinated. Mothers with intermediate, secondary, university and higher educa-tion were 2.0 times more likely to report correct vaccination of their children than were those with no schooling or with primary schooling. In this multivariate analysis, the socio-economic status did not have a unique association with vac-cination status. The variables mother awareness and availability of a vaccination card were excluded because of the skewed fre-quency distribution of these variables.

\section{Discussion:}

Vaccination coverage is highest among children whose mothers have a secondary or higher education. Utilization is higher when vacci-nation centers are easily accessible and provide good quality care ${ }^{8,9}$. Studies have shown that fixed immunization clin-ics often fail to reach those children who are at highest risk, i.e. those who fail to attend health centres ${ }^{10-12}$. Studies done in West Bengal and Delhi indicate that incorrect information regarding immunization of child during illness leads to non/partial immunization ${ }^{14,15}$. Freeman ${ }^{13}$ reported that provision of information to mothers regarding when to start the immunization and how often the child should be immunized were the key factors in determining immunization status. Maternal education was found to be positively associated with the knowledge about immunization, but was not significantly associated with actual immunization practice ${ }^{13}$. In the present study, the correct age specific vac-cination coverage rate among children under 2 years of age was found to be $60 \%$ for 3PENTA \& 3 Polio, $50 \%$ for 1 $\mathrm{BCG}$, and $40 \%$ for 1 measles vaccine. The principal factors affecting the immunization status of these chil-dren in terms of magnitude were area of accessibility to vaccination services in terms of walking time to the nearest place of vaccination, the child's age, age of the 
mother, and the mother's education. . Other studies in developing countries have also suggested that walking or traveling time and distance are key factors that influence the utilization of healthcare services ${ }^{16,17}$. Most people will not travel further than five kilometers to basic preventive and curative care ${ }^{18,19}$. Substantial differences in correct vaccination rates were found for chil-dren of literate and illiterate mothers and the high-est percentage of children who had received the correct vaccines were owned by literate mothers. It could also be attributed to the lack of awareness of the importance of vacci-nation among illiterate mothers in comparison to those who are educated as indicated by this research.

Vaccination rates also increased with an increase in age of the child. This may be due to the fact that women tend not to vaccinate young children due to a fear of the side effects of the vaccines, which seems to reflect a gap in knowl-edge regarding vaccination. Studies have shown that increasing maternal knowledge regarding vaccines im-proves immunization status 19,20 .

Maternal age was also found to have a relationship with the immunization status of the children. Children of older mothers had higher rates of correct immunization than had the children of younger. The age differences were greatest for BCG and measles vac-cines. The mother's awareness of the importance of vaccination and the avail-ability of a vaccination card showed a strong relationship with correct vaccina-tion status. Only 60\% mothers in this study could show the vaccination card of their children. Availability of the vaccination card may facilitate the follow up of different vaccines doses, remind mothers to avoid dropout doses and hence encourage them to complete the vaccination of their children.

Worldwide many studies regarding children immunization showed that successful immunization depends on parents positive attitude and knowledge ${ }^{21,22}$. Though the coverage rate was good in our study, but still there is an urgent need to increase the coverage of UIP (universal immunization program) vaccines so that not a single child remains partial/immunized and vulnerable to vaccine preventable diseases (VPDs).

In our study it was seen that health workers were the main source of information (88\%). Similar findings were seen in their studies where paramedics were seen as the main source of information. In our study $80 \%$ mothers considered that immunization was important and beneficial as it protects a child against diseases. Similar findings were seen in a study done in Congo. In our study, majority of mothers showed positive attitude towards immunization. This positive attitude about vaccination is reported in many previous studies as well, from developing and developed countries and range from $80-98 \%$ in different studies $^{23,24}$.

In our study, $88.76 \%$ of children were fully immunized. Zelaya-Bonilla et al. ${ }^{25}$ warned that a positive attitude is not a guarantee for full immunization. In our study, mothers showed more trust in government health facilities for vaccinating their children and showed compliance to health worker's instructions. This finding suggests a unique opportunity to improve the knowledge of mothers by improving the knowledge of health workers via regular trainings and awareness programmes. Moreover, we found that $66 \%$ of mothers themselves took decisions regarding immunizing their children, so more focus should be on improving their practices and knowledge.

\section{Conclusion:}

The study concluded that mothers' level of education, occupation, age of the mother, frequency of reading a news paper or magazine were significant household characteristics associated with immunization status of children 12-23 months old. In light of the above conclusion, the study recommends that people should be sensitized on the need to have all children fully immunized in order to prevent childhood deaths and life-long disability, improvement of interpersonal communication between health workers and mothers' so as to reduce missed chances and drop outs, improve 
on the child health care card retention by the mothers, mothers should be encouraged to give birth at health centres so as to have access to health facilities for example the first clinical contact where a child receives BCG and two drops of OPV and improve on the health infrastructure, motivate workers, promote parents participation by the government of Bangladesh.

\section{Acknowledgements:}

We are very much thankful to the $4^{\text {th }}$ year MBBS students (K-65) of Dhaka Medical College, Dhaka, who collected data and helped us at different stages of the work.

\section{References:}

1. World Health Organization. The world health report 2000 - Health systems: improving performance. Geneva: WHO; 2000.

2. UNICEF. The invisible child: a look at the urban child in Delhi. New Delhi: UNICEF; 1990.

3. World Health Organization. Media centre. Global Alliance for vaccines and immunization (GAVI) (online) 2004.

4. World Health Organization. Immunization, vaccines and biologicals. WHO; Geneva: WHO; 2007.

5. Singh KK, Mathew MM, Bhalerao VR. Impact of community-based Immunization services. J Postgrad Med 1986; 32(3); 131-3.

6. Rahman M, Islam MA, Mahalanabis D. Mothers' knowledge about vaccine preventable diseases and immunization coverage in a population with high rates of illiteracy. J Trop Pediatr 1995; 41(6): 376-8

7. Wang YY, Wang Y, Zhang JX, Kang CY, Duan P. Status of mother's KAP on child immunization in minority areas, Guizhou Province. [Article in Chinese] [Abstract]. Beijing Da Xue Bao 2007; 39 : 136-9.

8. Tandon B, Gandhi N. Immunisation coverage in India for areas served by integrated child devel-opment services programme. Bull World Health Organ 1992; 70: 461-5.

9. Cutts FT, Kortbeek S. Malalane R, Penicele P, Gin-gell K. Developing appropriate strategies for EPI: a case study from Mozambique. Health Policy Plan 1988; 3(4): 291-301.

10. Henderson RH. Vaccinations in the health strate-gies of developing countries. Scand J Infect Dis 1990; 76: 7-14.
11. Ekunwe EO. Expanding immunization coverage through improved clinic procedures. World Health Forum 1984; 5: 361-3.

12. Zachariah PS, Cowan B, Dhillion H. Limitations of the under-fives' clinics in a comprehensive health care programme. J Trop Pediatr 1980; 26(4): 144-9.

13. Freeman PA, Thomason JA, Bukenya GB. Factors affecting the use of immunization among urban settlement dwellers in Papua New Guinea. P N G Med J 1992; 35(3): 179-85.

14. Mukherjee B, Ray SK, Kar M, Mandal A, Mitra J, Biswas R. Coverage evaluation surveys amongst children in some blocks of West Bengal. Indian $\mathrm{J}$ Public Health 1990; 34(4): 209-14.

15. Bhattacharjee J, Singh J, Sharma RS. Reasons for immunization failure in infants of North India. Indian J Community Med 1993; 18(4): 160-3.

16. Manjunath U, Pareek RP. Maternal knowledge and perceptions about the routine immunization program: a study in a semiurban area in Rajasthan. Indian J Med Sci 2003; 57(4): 158-63.

17. Singh MC, Badole CM, Singh MP. Immunization coverage and the knowledge and practices of mothers regarding immunization in rural area. Indian J Public Health 1994; 38(3): 103-7.

18. Quaiyum MA, Tunon C, Hel Baqui A, Quayyum Z, Khatun J. Impact of national immunization days on polio related knowledge and practice of urban women in Bangladesh. Health Policy Plan 1997; 12(4): 363-71.

19. Wilson JB, Collison AH, Richardson D, Kwofie G, Senah KA, Tinkorang EK. The maternity home waiting concept: the Nsawam, Ghana experience. Int J Obstet- Gynecol 1997; 59(suppl 2): 165-72.

20. Evers DB. Teaching mothers about childhood immunizations. Am J Matern Child Nurs 2001; 26: 253-6.

21. Angelillo IF, Ricciardia G, Rossi P, Pantisano P, Langiano E, Pavia M. Mothers and vaccination; Knowledge, Attitude and behavior in Italy. Bull World Health Organ 1999; 77: 224-9.

22. Nisar N, Mirza M, Qadri MH. Knowledge, Attitude and Practices of mothers regarding immunization of one year old child at Mawatch Goth, Kemari Town, Karachi. Pak J Med Sci 2010; 26(1): 183-6.

23. Bonanni $\mathrm{P}$, Bergamini M. Factors influencing vaccine uptake in Italy. Vaccine 2000; 20(1): 508-12.

24. Fitch P, Racine A. Parental beliefs about vaccination among an ethnically diverse innercity population. J Natl Med Assoc 2004; 96(8): 1047-50.

25. Zelaya-Bonilla JE, Mata-Gamarra JI, Mills-Booth E. La perception de la vaccination par les meres au Honduras. [Article in French] [Abstract]. Les Carnets de L'enfance 1985; 69/72: 457-68. 